\title{
Methods of Estimating the Effect of Integral Motorcycle Helmets on Physiological and Psychological Performance
}

\author{
Anna Bogdan \\ Iwona Sudoł-Szopińska \\ Anna tuczak \\ Maria Konarska \\ Piotr Pietrowski
}

\section{Central Institute for Labour Protection - National Research Institute (CIOP-PIB), Poland}

This article proposes a method for a comprehensive assessment of the effect of integral motorcycle helmets on physiological and cognitive responses of motorcyclists. To verify the reliability of commonly used tests, we conducted experiments with 5 motorcyclists. We recorded changes in physiological parameters (heart rate, local skin temperature, core temperature, air temperature, relative humidity in the space between the helmet and the surface of the head, and the concentration of $\mathrm{O}_{2}$ and $\mathrm{CO}_{2}$ under the helmet) and in psychological parameters (motorcyclists' reflexes, fatigue, perceptiveness and mood). We also studied changes in the motorcyclists' subjective sensation of thermal comfort. The results made it possible to identify reliable parameters for assessing the effect of integral helmets on performance, i.e., physiological factors (head skin temperature, internal temperature and concentration of $\mathrm{O}_{2}$ and $\mathrm{CO}_{2}$ under the helmet) and on psychomotor factors (reaction time, attention and vigilance, work performance, concentration and a subjective feeling of mood and fatigue).

integral helmet motorcyclist thermophysiology motorcyclist cognitive functions physiological response

\section{INTRODUCTION}

Motorcycles and scooters are increasingly popular means of transport in cities and urban agglomerations. For safety reasons, helmets are mandatory. Liu, Ivers, Norton, et al. showed that a helmet reduced the risk of head injury by $\sim 72 \%$ [1]. Moreover, motorcyclists in helmets and other protective equipment are generally more safety conscious [2].

To ensure maximum protection in case of a fall or collision, the helmet should tightly protect the whole surface of the head, including the face and ears. The space thus created inside an integral hel- met can gather numerous noxious substances (mainly $\mathrm{CO}_{2}$ ), which leads to a rise in temperature. This, in turn, can impair a motorcyclist's psychophysical performance.

Helmets are tested against mechanical durability [3]. Their effect on the physical and psychological performance was studied indirectly when determining various aspects: heat flux in manikin tests [4], influence of hair growth and air velocity on heat flux [5], rebreathing [6], concentration of gases under the helmet [7], sources and levels of noise under the helmet in a wind tunnel [8], vision capability and hearing [9], arrival time judgements

\footnotetext{
This work was carried out within COST Action 357 Prohelm "Accident Prevention Option with Motorcycle Helmets", with financial support from grant COST/199/2006 from the Ministry of Science and Higher Education of Poland.

Correspondence and requests for offprints should be sent to Anna Bogdan, CIOP-PIB, ul. Czerniakowska 16, 00-701 Warszawa, Poland. E-mail: anbog@ciop.pl.
} 
[10], etc. The objective of our experiments was to determine a sufficiently sensitive and comprehensive method for assessing the impact of integral motorcycle helmets on human psychomotor and physiological reactions that could also be used for fewer subjects. We assumed that the effect of integral helmets on human psychomotor and physiological reactions would be assessed against motorcyclists' thermophysiological reactions and cognitive functions.

\section{MEASUREMENT STRATEGY}

We divided the task into two parts. The first one was to determine the physiological parameters of a motorcyclist to be considered when evaluating the thermal environment and microclimate under the helmet. The second one was to verify the usefulness of selected psychological tests commonly used to identify the cognitive functions of motorcyclists.

On the basis of interviews with motorcyclists (police officers) and literature [11, 12, 13, 14, 15, $16,17,18]$, we decided to carry out experiments with human subjects in a climatic chamber under conditions generally recognized as potentially most detrimental in terms of their effect on the cognitive functions of motorcyclists, i.e., in an environment corresponding to summer weather, with a noise level characteristic for an urban agglomeration and with low air velocity.

\subsection{Material and Equipment}

The experiments involved 5 healthy and physically fit male police officers performing their duties on motorcycles for $\sim 11$ years. Table 1 shows their detailed characteristics.
Before testing, the subjects underwent preliminary medical tests: an electrocardiogram, blood pressure measurement and physical endurance assessment against maximum oxygen consumption $\left(V \mathrm{O}_{2 \max }\right) . V \mathrm{O}_{2 \max }$ was measured with the Åstrand method [19], considering also the age coefficient. The results of the tests in all subjects were within acceptable limits. During tests, the subjects wore motorcycle uniforms in compliance with Poland's regulation [20]. The uniform consisted of trousers, leather boots and gloves and, optionally, a jacket and an integral helmet. The tests took place in a WK 40-70 climatic chamber (Weiss, Germany) with noise-generating and monitoring equipment: power amplifiers (Crown Audio, USA); Tonsil Voyager speakers (Tonsil Acoustic Company, Poland); a 1027 generator, a 4190 microphone, a 2669 Mic Preamp, a spectrum analyser measurement system, a 2236 sound level meter, a calibrator and a set of meters measuring and recording parameters of microclimate workstations (all from Brüel \& Kjæl, Denmark). For physiological and psychological measurements, we used the following equipment: an FT 2000 cardiometer for measuring heart rate (HR), local skin temperature and core temperature (Emtel, Poland); a Hygrolab thermometer and hygrometer to measure temperature and relative humidity (RH) in the space between the skin and the clothing or the helmet (Rotronic, Switzerland) and a MCZR/ATB 1.0 meter of choice reaction time (ATB Info-Elektro, Poland).

\subsection{Procedures}

The experiments covered two variants of the environment: thermoneutral and a combined influence of heat and noise (to examine the poten-

\section{TABLE 1. Subjects' Characteristics}

\begin{tabular}{lccccc}
\hline Subject & Age (years) & Height $(\mathbf{m})$ & Weight $(\mathbf{k g})$ & BMI & Body Area $\left(\mathbf{m}^{\mathbf{2}}\right)$ \\
\hline 1 & 31 & 1.87 & 89.5 & 25.6 & 2.15 \\
2 & 34 & 1.84 & 106.8 & 31.5 & 2.29 \\
3 & 30 & 1.81 & 85.1 & 26.0 & 2.05 \\
4 & 36 & 1.80 & 89.4 & 27.6 & 2.09 \\
5 & 35 & 1.86 & 121.1 & 35.0 & 2.43 \\
\hline
\end{tabular}

Notes. BMl—body mass index (kilograms per square metre). 
tial adverse effect of a hot environment). Furthermore, to examine the potential effect of clothing and a helmet on a motorcyclist's performance, we used two types of clothing: a full motorcycle uniform (in thermoneutral conditions) and a motorcycle uniform without a jacket (in an environment of heat and noise). Each subject participated in four measurement sessions (variants, V):

- V1-in a motorcycle uniform without a helmet, in thermoneutral conditions, i.e., temperature $20^{\circ} \mathrm{C}$, air velocity $0.2 \mathrm{~m} / \mathrm{s}$, RH 50\%;

- V2-in a motorcycle uniform without a jacket or a helmet; temperature $30{ }^{\circ} \mathrm{C}$, air velocity $2.0 \mathrm{~m} / \mathrm{s}$, RH $45 \%$; levels of heat and noise $(88 \mathrm{~dB})$ corresponding to those of an urban agglomeration;

- V3-in a motorcycle uniform with a helmet, in thermoneutral conditions, i.e., temperature $20{ }^{\circ} \mathrm{C}$, air velocity $0.2 \mathrm{~m} / \mathrm{s}, \mathrm{RH} 50 \%$;

- V4 - in a motorcycle uniform with a helmet, without a jacket; temperature $30^{\circ} \mathrm{C}$, air velocity $2.0 \mathrm{~m} / \mathrm{s}$, RH $45 \%$; levels of heat and noise $(88 \mathrm{~dB})$ corresponding to those of an urban agglomeration.

During each test, the subjects sat in the climatic chamber. Each test had three phases:

- A: thermoneutral conditions;

- B: conditions in V1, V2, V3 or V4;

- $\mathrm{C}$ : thermoneutral conditions.
For each test, the subjects did a set of psychological tests (tests $1-5$, see section 2.4). Table 2 shows selected physiological parameters and parameters of the physical microclimate under the helmet (in relevant variants), which we recorded at the same time. The whole experiment lasted $\sim 2 \mathrm{~h}$.

\subsection{Physiological Tests}

During the experiments, we monitored continuously the following physiological reactions of the motorcyclists: HR, local temperature of the skin measured in 10 points, internal temperature measured in the external auditory canal (core temperature), temperature and RH in the space between the helmet and the head, and the concentration of $\mathrm{CO}_{2}$ and $\mathrm{O}_{2}$ under the helmet. Figure 1 shows the location of the sensors.

The subjects were under constant medical surveillance during the tests; there was visual and verbal contact. Even though the conditions did not entail any serious risk of exceeding permissible physiological parameters, we expected to discontinue tests in case of any of the following: internal temperature of over $39^{\circ} \mathrm{C}$, HR over $90 \%$ of the maximum value for a given age, subjective symptoms preventing continuation of the test or other medical recommendations. The Bioethics Committee at the Regional Medical Chamber in Warsaw, Poland, approved that method.

TABLE 2. Diagram of a Single Experiment

\begin{tabular}{|c|c|c|c|}
\hline \multirow[b]{2}{*}{ Phase } & \multirow[b]{2}{*}{ Environment During Test } & \multicolumn{2}{|c|}{ Test } \\
\hline & & Psychological Parameter & Subjective Sensation \\
\hline A & thermoneutral & $\begin{array}{l}1 \\
2 \\
3 \\
4 \\
5\end{array}$ & $\begin{array}{l}\mathrm{A} \\
\mathrm{B} \\
\mathrm{C}\end{array}$ \\
\hline B & V1, V2, V3, V4 & $\begin{array}{l}1 \\
2 \\
3 \\
4 \\
5\end{array}$ & $\begin{array}{l}\mathrm{A} \\
\mathrm{B} \\
\mathrm{C}\end{array}$ \\
\hline C & thermoneutral & $\begin{array}{l}1 \\
2\end{array}$ & $\begin{array}{l}\mathrm{A} \\
\mathrm{B} \\
\mathrm{C}\end{array}$ \\
\hline
\end{tabular}

Notes. V1, V2, V2, V4-variants; physiological parameters were measured continuously; for details, see sections 2.2, 2.4, 2.5 . 

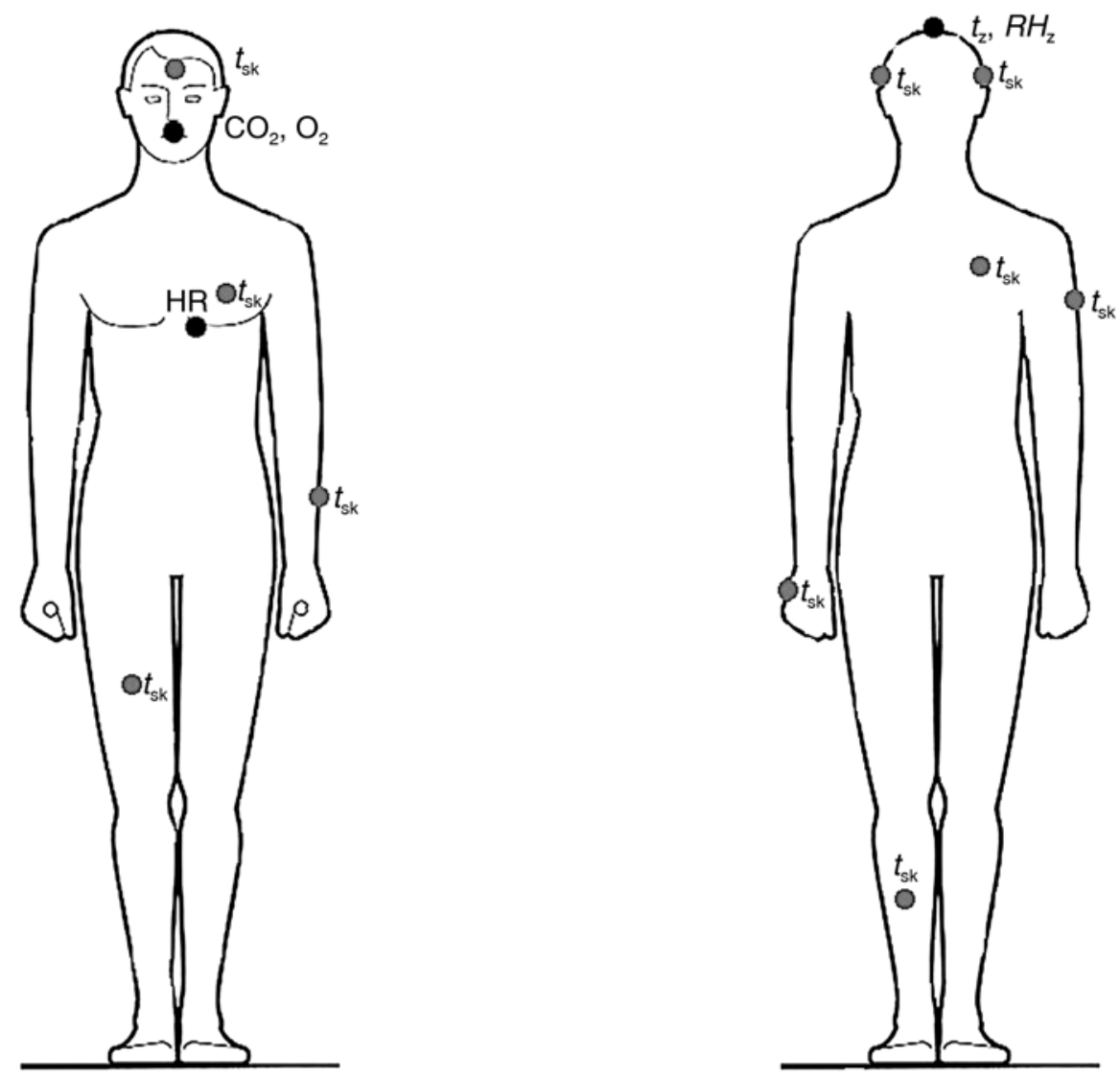

Figure 1. Location of sensors for measuring physiological parameters. Notes. $t_{\mathrm{sk}}$-skin temperature; $t_{\mathrm{z}}$-temperature in the space between the head and the helmet; $R H_{\mathrm{z}}$-humidity in the space between the head and the helmet; $\mathrm{CO}_{2}, \mathrm{O}_{2}$ - concentration of $\mathrm{CO}_{2}$ and $\mathrm{O}_{2}$, respectively; $\mathrm{HR}$-heart rate.

\subsection{Cognitive Functions and Psychomotor Performance Tests}

The experiments included the following psychological tests:

- test 1 (3 min): choice reaction time measuring a motorcyclist's reaction time, i.e., the period between the stimulus and the response, estimated with the parameter of mean reaction time (milliseconds) and effective range, i.e., the difference between the shortest and longest reaction time (milliseconds) [21];

- test 2 (20 min): ALS work performance measuring the rate of fatigue growth, indicated by solved (the number of solved tasks used to measure work speed) accrual of solved tasks (average increase in correctly performed tasks per minute, expressed with a gradient coefficient of a regression line) and the ratio of mistakes in the total number of performed tasks (\%) [22];
- test 3 (10 min): SIGNAL attention and vigilance measuring cognitive processes, i.e., concentration and ability to maintain vigilance, also in monotonous conditions; the number of solved tasks was the performance indicator-reactions in response to an important stimulus, omitted - the number of stimuli to which the subjects failed to react [23];

- test 4 (2 min): Piéron's attention measuring performance of cognitive processes including perceptiveness; the ratio of correct answers to the number of all answers in the test (\%) was the performance indicator, omitted - the number of symbols the subjects failed to mark [24];

- test 5 (3 min): Grandjean's scale measuring a subjective diagnosis of mood and fatigue, used as an indicator of mental load resulting from tasks requiring a mental activity [25]. 


\subsection{Thermal and Comfort Sensation Tests}

We measured subjective evaluation of temperature and $\mathrm{RH}$ with

- test A with a 7-point thermal sensation scale: -3 (cold), -2 (cool), -1 (slightly cool), 0 (neutral), +1 (slightly warm), +2 (warm), +3 (hot) [26];

- test B with a 4-point clothing dampness sensation: 1 (dry), 2 (slightly damp), 3 (damp), 4 (wet) [27];

- test $\mathrm{C}$ with an 8-point skin dampness sensation scale: 1 (more dry than normal), 2 (normal dryness), 3 (sweat and back slightly wet), 4 (sweat and back wet), 5 (body wet), 6 (body wet, clothing sticks on the skin), 7 (sweat runs somewhere off), 8 (sweat runs off many places) [27].

\subsection{Statistical Analysis}

We did a statistical analysis of the psychological tests with the Kolmogorov-Smirnov test to verify the normal distribution hypothesis and an analysis of variance (ANOVA) (single classification) for group means to verify the effect of factors characteristic for given test variants on the results of the psychological tests. Where distribution approximation for normal distributions of empiric random variables was not applicable or where the condition of variance homogeneity was not fulfilled (Bartlett's and Cochrane's tests), we used the Kruskal-Wallis (K-W) non-parametric method comparing empiric distribution of analysed random variables and, in the case of two distributions, also a rating test. Because there was no normal distribution (Shapiro-Wilk test), we used the Wilcoxon signed-rank test to analyse most of the examined physiological parameters (HR, skin temperature, core temperature, head skin temperature and temperature and $\mathrm{RH}$ in the space between the helmet and the head). The goal of the analysis was to determine if there were any significant differences between the mean values of the physiological parameters during experiments with and without a helmet, separately for the variants in thermoneutral conditions and in a hot environment.

\section{RESULTS}

\subsection{Physiological Tests}

Figures 2-3 present average values of mean skin temperature of the 5 subjects for different experiments. We observed the highest mean skin temperature $\left(34.1{ }^{\circ} \mathrm{C}\right)$ for a thermoneutral environment, with a helmet. For the variant without a helmet, the temperature was lower by $0.76{ }^{\circ} \mathrm{C}$. In an environment of heat and noise, the temperature for the test variants with and without a helmet differed by $0.22{ }^{\circ} \mathrm{C}$. Such a considerably lower variation is attributable to the fact that the subjects did not wear jackets and to a markedly higher air velocity in the climatic chamber in an environment of heat and noise.

Figure 4 shows the results of a statistical analysis of mean skin temperature. There are significant differences between the experiments with and without a helmet in thermoneutral conditions. The differences between mean skin temperatures during experiments in thermoneutral conditions were significant at $p<.05$. There were no significant differences in the mean skin temperature in the hot environment, so transfer of heat into the external environment was impossible. Both with and without a helmet, the transfer of heat generated by the body was equally difficult during experiments in a hot environment. Measurements of mean skin temperature revealed that this was a reliable indicator for evaluating the effect of an integral helmet on a motorcyclist's physiological parameters.

Figures 4-5 present mean core temperatures for all subjects in different variants of the experiment. The lowest mean core temperature $\left(36{ }^{\circ} \mathrm{C}\right)$ was recorded in thermoneutral conditions, without a helmet; with a helmet, the temperature increased by $0.65{ }^{\circ} \mathrm{C}$. During tests in a hot environment, the difference between mean values for variants with and without a helmet was much lower $\left(0.23{ }^{\circ} \mathrm{C}\right)$. This relationship can result from the fact that the subjects did not wear jackets in tests in a hot environment. Moreover, air velocity was considerably higher $(2 \mathrm{~m} / \mathrm{s})$ in the climatic chamber than in a thermoneutral environment. 


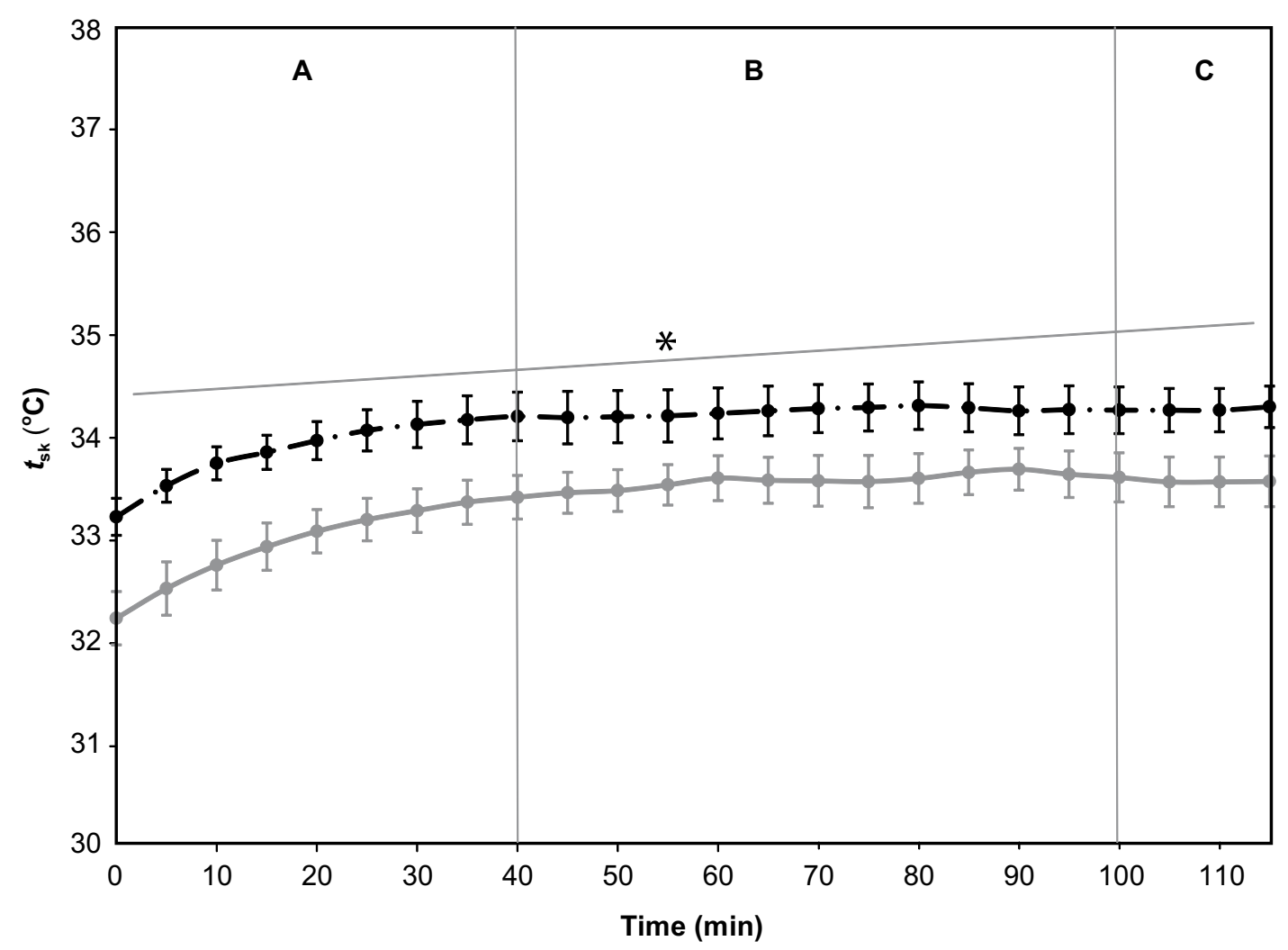

Figure 2. Change in mean skin temperature for 5 subjects in thermoneutral conditions. Notes. ${ }^{*} p<.05 ; \mathrm{A}, \mathrm{B}, \mathrm{C}$ - phases of the experiment; grey line—subject without a helmet; black line—subject with a helmet.

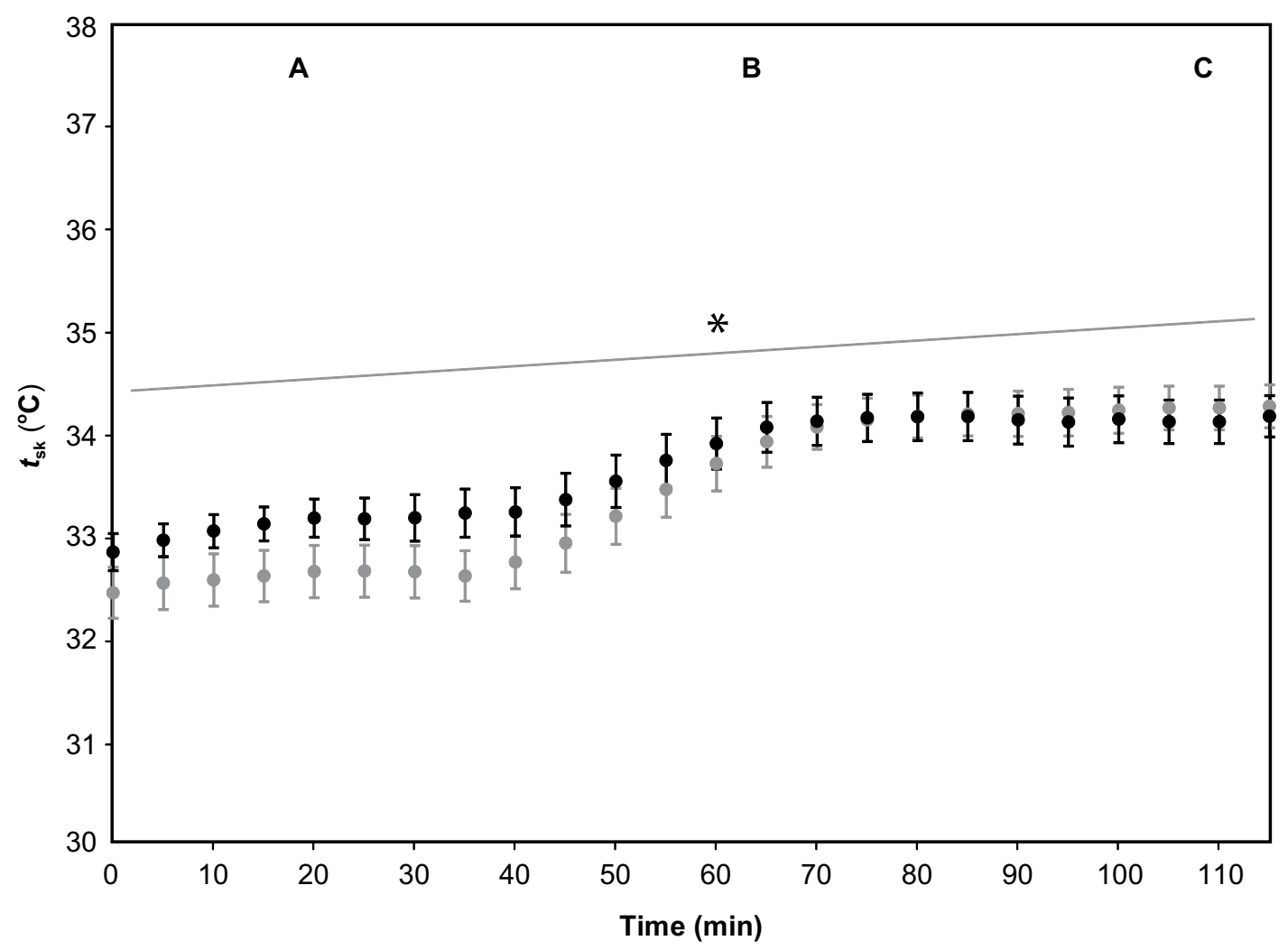

Figure 3. Change in mean skin temperature for 5 subjects in heat and noise. Notes. ${ }^{*} p<.05$; A, B, $C$ - phases of the experiment; grey line-subject without a helmet; black line - subject with a helmet. 


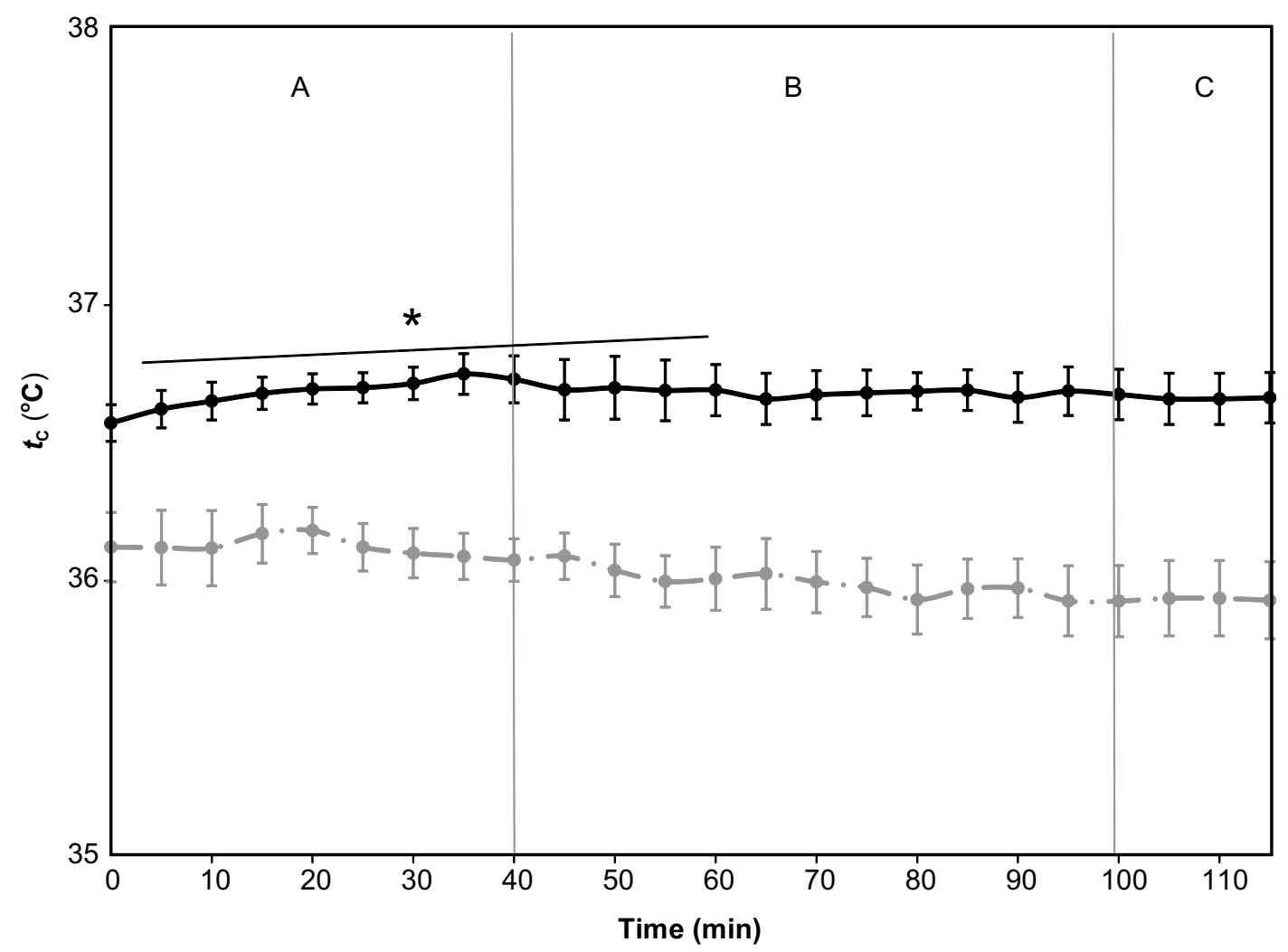

Figure 4. Change in mean core temperature for 5 subjects in thermoneutral conditions. Notes. ${ }^{*} p<.05 ; \mathrm{A}, \mathrm{B}, \mathrm{C}$ - phases of the experiment; grey line-subject without a helmet; black line-subject with a helmet; $t_{c}$-core temperature.

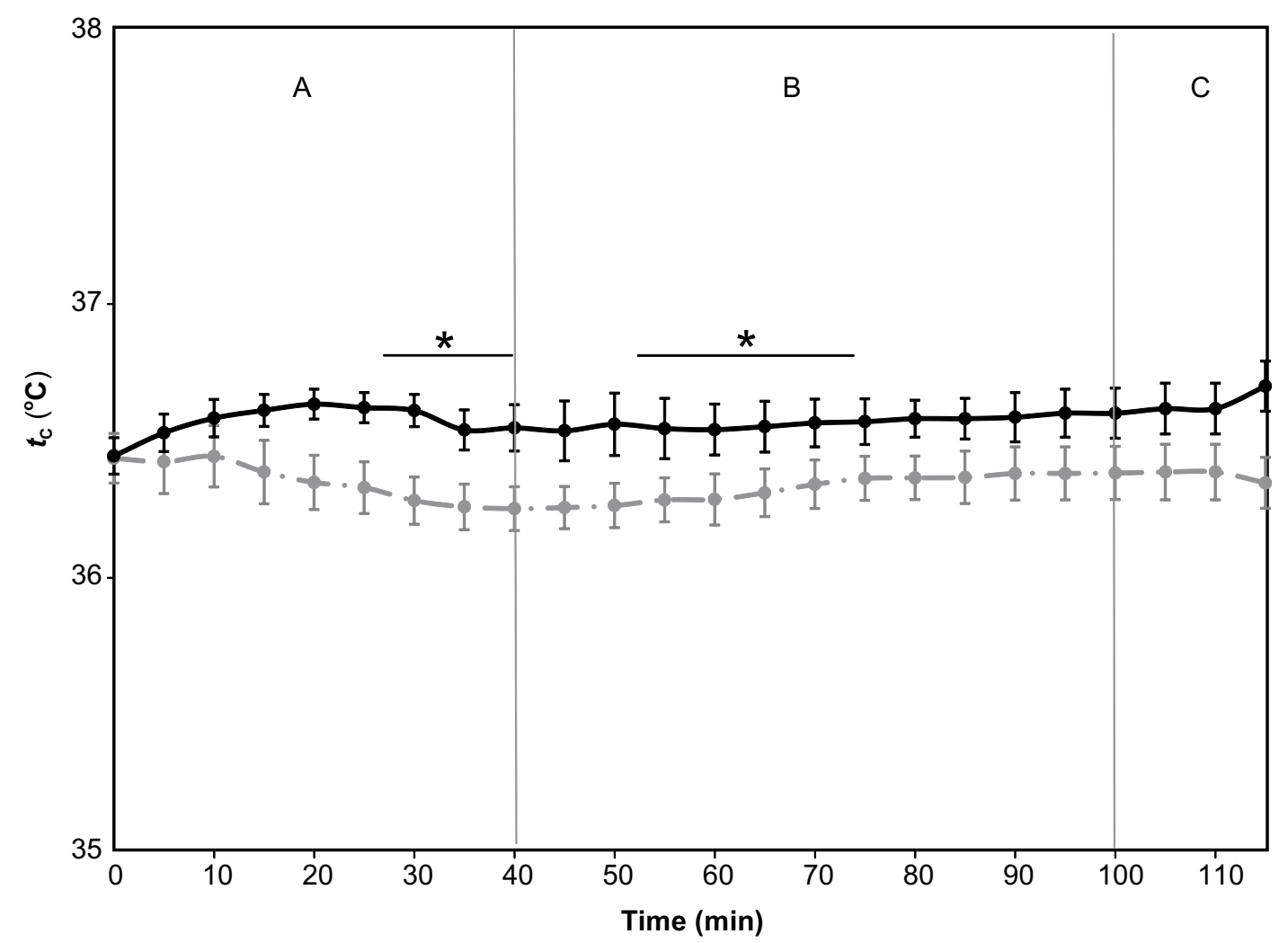

Figure 5. Change in mean internal temperature for 5 subjects in heat and noise. Notes. ${ }^{*} p<.05 ; A$, B, C-phases of the experiment; grey line-subject without a helmet; black line—subject with a helmet; $t_{\mathrm{c}}$-core temperature. 
The results of a statistical analysis of mean core temperature reveal differences between the tests performed with and without a helmet. Those differences are significant for thermoneutral conditions until the 60th minute and for hot conditions until the 75th minute of the experiment. The differences between mean core temperatures were significant at $p<.05$. Therefore, it can be assumed that core temperature is a reliable indicator in terms of assessing the effect of a helmet on a motorcyclist's performance.

Figures 6-7 show mean values of temperature changes of head skin for 5 subjects. In a thermoneutral environment, the difference between mean head skin temperatures with and without a helmet was $2.80^{\circ} \mathrm{C}$. The mean value for a hot environment and noise, determined in the same way, was $1.65^{\circ} \mathrm{C}$. It should also be noted that head temperature in the variant with a helmet, irrespective of the thermal environment, was $\sim 36^{\circ} \mathrm{C}$.

The results of a statistical analysis of mean head skin temperature show differences between variants with and without a helmet. The differences are significant both for thermoneutral con- ditions and for a hot environment. The differences between the values of mean head skin temperature are significant at $p<.05$. Therefore, it can be assumed that head skin temperature during the experiment should be analysed very precisely. Using more sensors under the helmet is recommended; however, the subject's comfort is important, too.

In the variant without a helmet, the concentration of $\mathrm{O}_{2}$ in the breathing zone remained stable at over $20 \%$. During variants with a helmet, the concentration of $\mathrm{O}_{2}$ in the first minutes of the experiment fell below 18\% (Figure 8). Those data confirm the existence of a space around the head, limited by the helmet, where the concentration of $\mathrm{O}_{2}$ decreases.

The results of a statistical analysis of the concentration of $\mathrm{O}_{2}$ in the breathing zone show differences between tests with and without a helmet. Those differences are statistically significant both for thermoneutral conditions and for a hot environment. The differences in the mean concentration of $\mathrm{O}_{2}$ in a user's breathing zone are significant at $p<.05$.

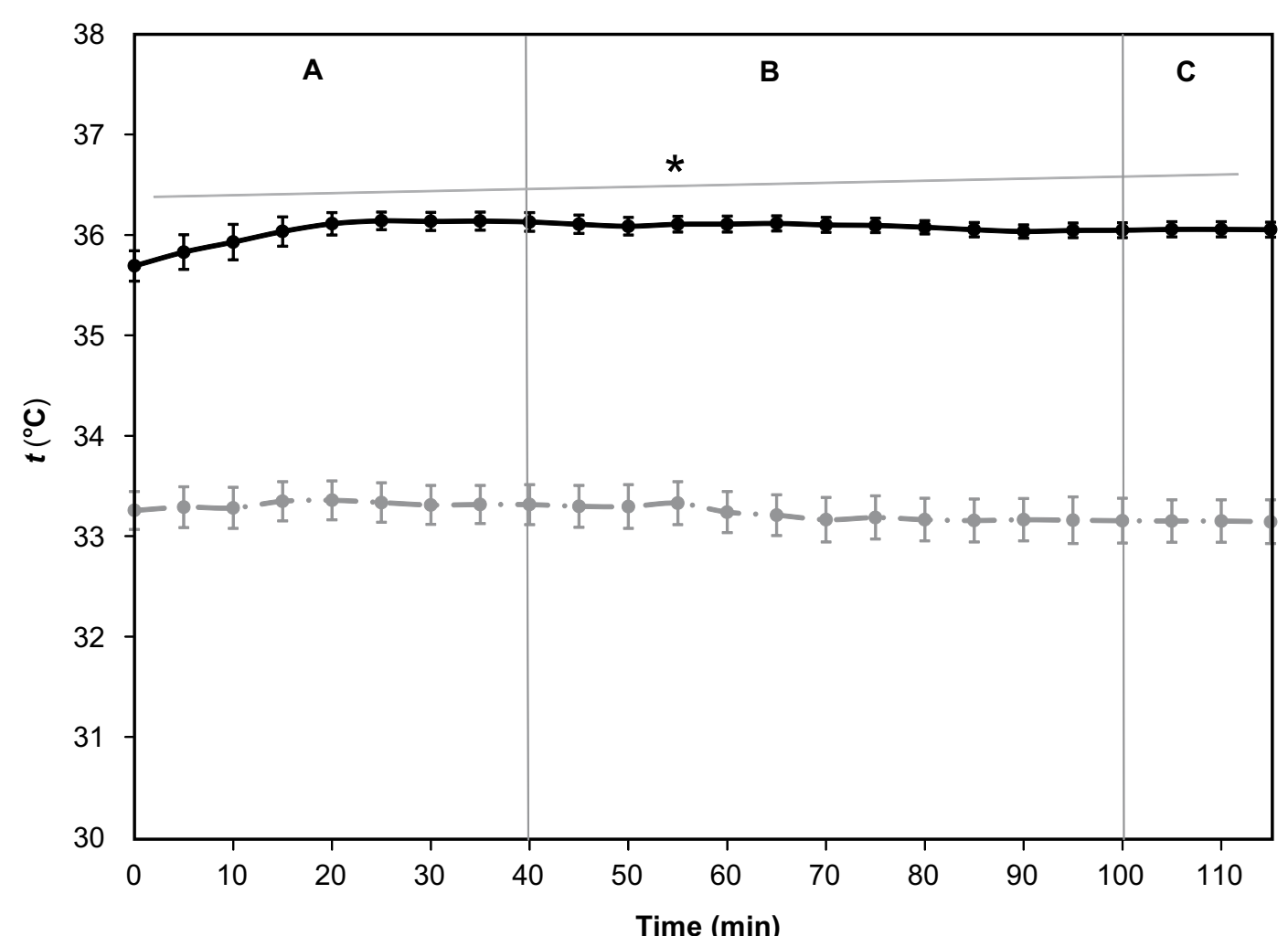

Figure 6. Change in mean head temperature for 5 subjects in thermoneutral conditions. Notes. ${ }^{*} p<.05 ; A, B, C$ - phases of the experiment; grey line-subject without a helmet; black line-subject with a helmet. 


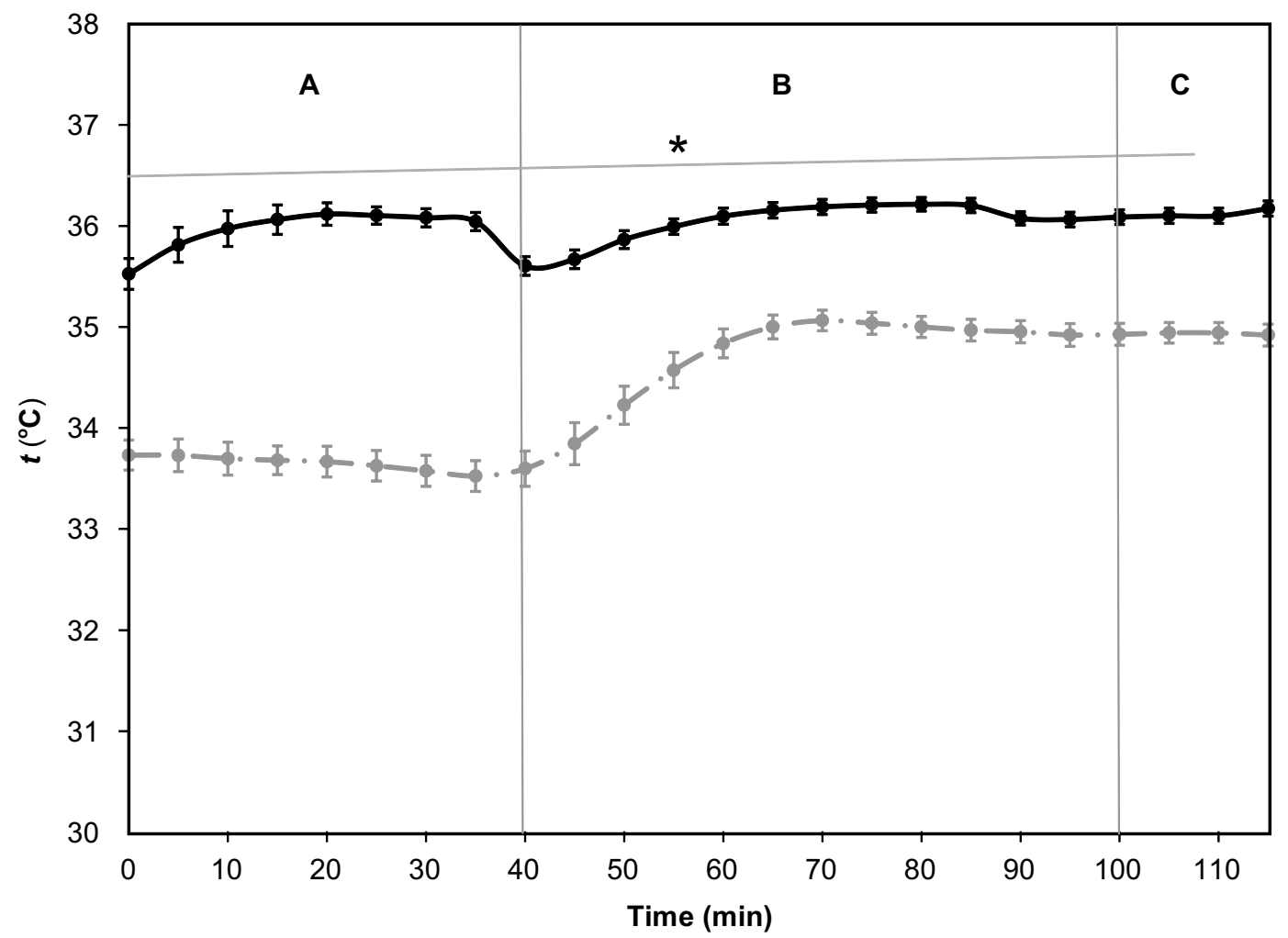

Figure 7. Change in mean head temperature for 5 subjects in heat and noise. Notes. ${ }^{*} p<.05 ; A, B$, C-phases of the experiment; grey line-subject without a helmet; black line—subject with a helmet.

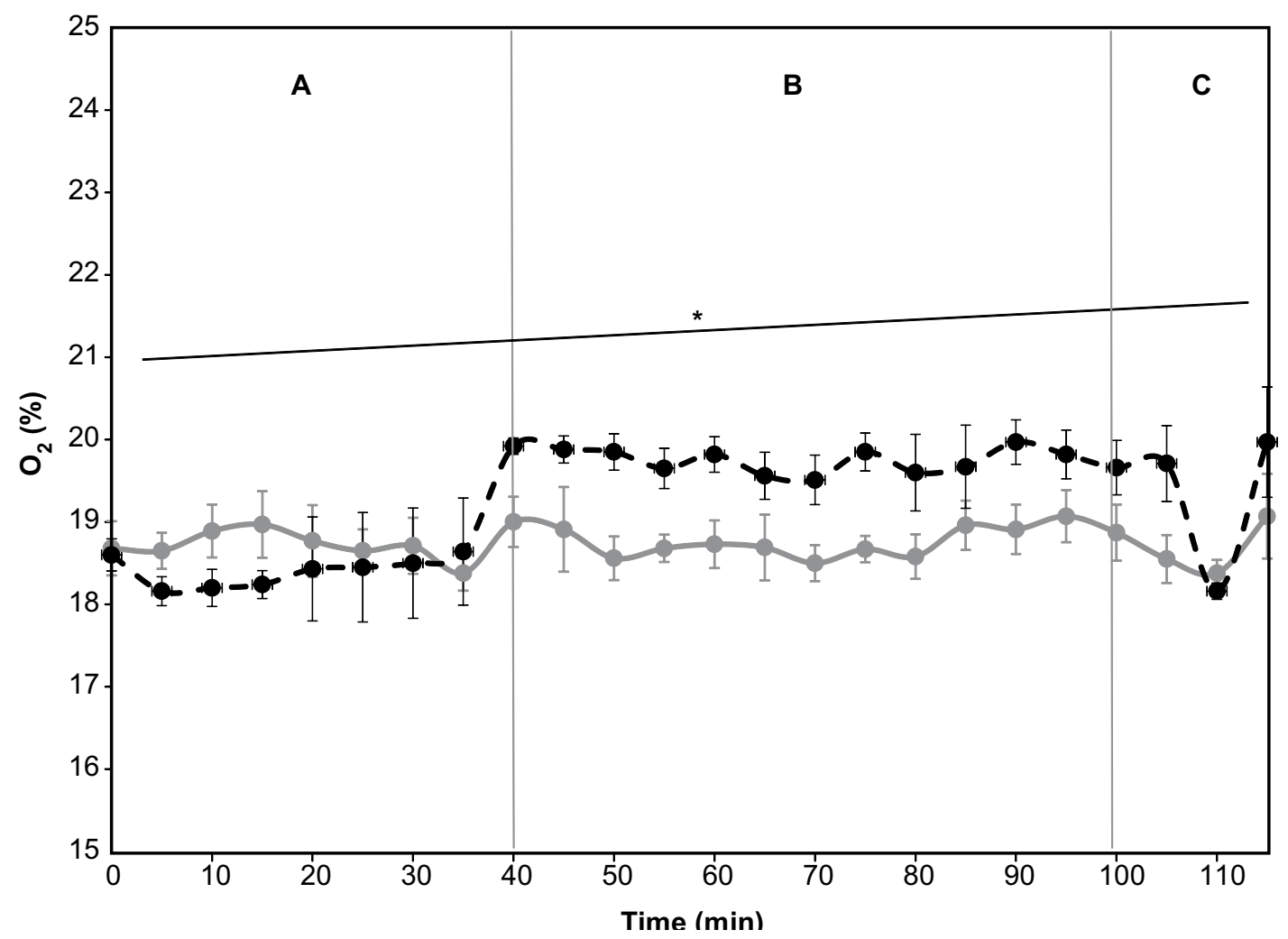

Figure 8. Change in concentration of $\mathrm{O}_{2}$ in subject's breathing zone. Notes. ${ }^{*} p<.05 ; \mathrm{A}, \mathrm{B}, \mathrm{C}-\mathrm{phases}$ of the experiment; grey line-thermoneutral environment; black line-hot environment. 
The $\mathrm{CO}_{2}$ absorption curves, describing changes in the concentration of $\mathrm{CO}_{2}$ in the user's breathing zone, indicate that in the test variant with a helmet, the concentration of $\mathrm{CO}_{2}$ in the breathing zone was higher than in the one without a helmet. This finding seems to confirm the existence of a limited space around the breathing zone of the subjects who wore a helmet during the relevant test (Figure 9). At the same time, we noted that in the test variant in a hot environment, with a helmet, the concentration of $\mathrm{CO}_{2}$ exceeded permissible limits by under $3 \%$ between the 10 th and 35 th minute of the experiment. The results of a statistical analysis of the concentration of $\mathrm{CO}_{2}$ in a user's breathing zone reveal differences between work with and without a helmet. Those differences are significant for thermoneutral conditions and also for a hot environment in the whole experiment. The differences between the mean values of the concentration of $\mathrm{CO}_{2}$ in the user's breathing zone are significant at $p<.05$. The concentration of $\mathrm{CO}_{2}$ measured in the immediate surroundings for each subject and for each test vari- ant was similar, i.e., the mean for the four test variants was $0.3 \%$. That result had no bearing on the values of the concentration of $\mathrm{CO}_{2}$ in the user's breathing zone. At the same time, we determined that the concentration of $\mathrm{O}_{2}$ and $\mathrm{CO}_{2}$ should be estimated during experiments on the effect of helmets on motorcyclists.

With regard to the remaining parameters, there were no significant changes in the test variants with and without a helmet. In a thermoneutral environment, with a helmet, the mean values of HR were higher by $2.7 \mathrm{bpm}$ (beats per minute) than the ones obtained in tests without a helmet. The mean values of HR in an environment of heat and noise, with a helmet, were higher by $\sim 0.9 \mathrm{bpm}$. Those values are not statistically significant. Similarly, we found no major impact of heat or a helmet on changes in HR. The permissible physiological limits of $\mathrm{HR}\left(\mathrm{HR}_{\max }\right)$ were not exceeded $\left(\mathrm{HR}_{\max }=200-\right.$ age $)$ in any test variant.

In all subjects, the increase in the temperature in the space between the helmet and the head was similar in moderate environment conditions: at

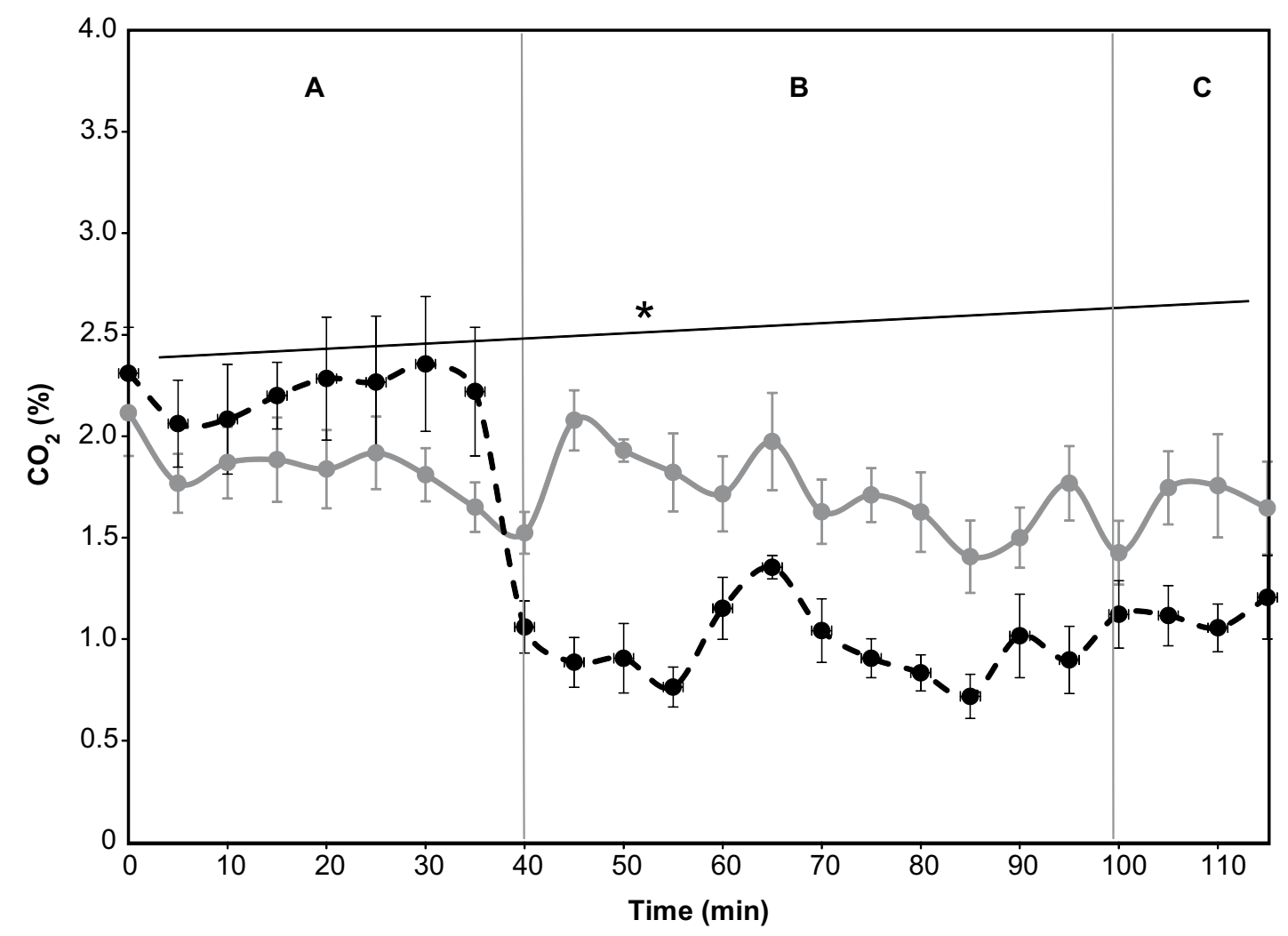

Figure 9. Change in concentration of $\mathrm{CO}_{2}$ in subject's breathing zone. Notes. ${ }^{*} p<.05 ; \mathrm{A}, \mathrm{B}, \mathrm{C}-$ phases of the experiment; grey line-thermoneutral environment; black line-hot environment. 
the end of the test, the temperature was $\sim 35.8 \pm 0.2^{\circ} \mathrm{C}$. In a hot environment with a high level of noise (despite no jacket during the test), we noted more distinct individual differences; the final mean value was $36.6 \pm 0.4{ }^{\circ} \mathrm{C}$. On average, the temperature under the helmet in a hot environment with a high level of noise was higher by $0.6{ }^{\circ} \mathrm{C}$ than in thermoneutral conditions. The results of a statistical analysis of the mean temperature in the space between the helmet and the head indicated no significant differences at $p<.05$ between the variants of the environment conditions, i.e., thermoneutral ones and those of heat and noise. In all test variants for all subjects, we observed a marked increase in RH in the space between the helmet and the head. This finding suggests that the lining inside helmets had no absorption properties, which resulted in considerable accumulation of humidity in the space under the helmet. In an environment of heat and noise, average $\mathrm{RH}$ under the helmet was 5\% lower than RH determined in moderate environment conditions. That is attributable to the fact that during experiments conducted in a hot environment the subjects did not wear jackets and as a result they did not sweat much. The results of a statistical analysis of mean RH in the space between the helmet and the head showed no statistically significant differences at $p<.05$ between the values determined in the conditions of moderate environment and in the conditions of heat and noise. Consequently, it can be concluded that RH in the space between the head and the helmet is not a reliable parameter in terms of evaluating the effect of the helmet worn in various thermal environments.

\subsection{Psychomotor Performance and Cognitive Function}

An analysis of variance of the results of test 3 revealed the following major statistical differences between V3 and V4:

- $\operatorname{solved}(F=2.164, p=.103)$ : wearing a helmet in an environment of heat and noise cooccurred with a considerably lower number of correctly solved tasks than wearing a helmet in thermoneutral conditions;
- $\operatorname{omitted}(F=2.820, p=.041)$ : wearing a helmet in an environment of heat and noise co-occurred with a considerably higher number of omissions than wearing a helmet in thermoneutral conditions.

An analysis of the results of test 5 demonstrated that in the case of mood, there were no significant differences in the distribution of the results obtained in four experiments $(\mathrm{K}-\mathrm{W}=6.03$, $p=.110$ ), which means that the type of experiment did not have any major bearing on the level of the subjects' mood. With regard to the distribution of the results of fatigue in individual variants of experiments, there were significant differences $(\mathrm{K}-\mathrm{W}=21.85, p<.001)$. The experiments showed that fatigue gradually intensified from test to test, i.e., fatigue was lowest in variant 1 (thermoneutral conditions, without a helmet) and highest in variant 4 (an environment of heat and noise, with a helmet).

Test 1 revealed no major differences between the mean in 5 policemen in four experiments (mean reaction time: $F=0.237, p<.001$; interval: $F=0.687, p=.563)$. Therefore, it can be concluded that variants did not influence complex reaction time test results. Consequently, it was not proved that environment conditions and wearing an integral helmet had an effect on the tested features.

An analysis of the results of test 2 showed that mean values of accrual in solutions obtained in the subjects in four variants did not reveal significant differences $(F=1.220, p=.310)$. Similarly, distributions of solved and mistakes obtained in four variants did not differ significantly $(\mathrm{K}-\mathrm{W}=0.12, p=.9893 ; \mathrm{K}-\mathrm{W}=6.02, p=.111$, respectively). Therefore, it can be concluded that the type of experiment, i.e., thermal conditions, noise, wearing or not wearing a helmet, had no effect on the level of attention and fatigue in the 5 subjects.

Test 4 showed no major differences between average test results in given experiment variants (correct answers: $F=0.008, p=.999$; omitted: $F=0.375, p=.772$ ). Therefore, the type of experiment did not differentiate the results of the perceptiveness test, which means the environment, 
noise and wearing or not wearing a helmet did not impact the level of perceptiveness.

\subsection{Subjective Thermal Sensation Assessment}

Thermal sensation and RH experienced by the subjects were comparable. Upon completion of the test in thermoneutral conditions with and without a helmet, the assessment of sensations was identical. In a hot environment, the assessment would deteriorate as the experiment progressed, particularly in the variant with a helmet. Each opinion on thermal sensations, clothes and skin humidity for a variant with a helmet was one degree higher as sensations deteriorated. The thermal sensation of the whole body was hot, clothes were slightly damp and body was wet (see section 2.5). Summing up, a helmet had no aggravating effect on thermal sensations and $\mathrm{RH}$ in a moderate environment, whereas in a hot environment it caused thermal discomfort.

\section{CONCLUSIONS}

Motorcycles are inherently unstable and require a higher level of concentration and shorter reaction time than four-wheel vehicles. In addition, a motorcyclist is more exposed to the weather and noise than a driver, which can have an additional adverse influence on concentration. A helmet is the only way to protect a motorcyclist's head against mechanical injuries in road collisions. However, adverse microclimate and breathing in gases generated under the helmet may aggravate motorcyclists' comfort and their cognitive functions. That is why developing appropriate research methods and increasing the number of experiments examining the effect of helmets and protective equipment is necessary to improve motorcyclists' safety on the road.

The methods of testing presented in this article make it possible to assess the impact of a helmet on physiological and cognitive parameters of motorcyclists. It has been proved that the parameters which should be analysed in tests of comfort and safety with helmets and with the participation of volunteers are (a) physiological indicators: head skin temperature, core temperature and the concentration of $\mathrm{O} 2$ and $\mathrm{CO}_{2}$ under the helmet; and (b) psychological indicators: reaction time, concentration and the subjective feeling of mood and fatigue.

Further research should include the following observations we made: (a) HR, temperature, and $\mathrm{RH}$ in the space between the helmet and the subject's head are not reliable indicators of changes caused by the helmet; a statistical analysis of those values showed that the differences determined in test variants with and without a helmet were statistically negligible; and (b) measuring internal temperature in the external auditory canal is characterized by a considerable uncertainty and subject-to-subject variability.

We performed tests with volunteers (policemen) in model conditions (parking in an urban agglomeration). The tests demonstrated an influence of a helmet on some physiological and cognitive functions of motorcyclists. Despite the fact that the surface of the head makes up only $10 \%$ of body surface, its temperature is significant for thermal comfort [18]. This is so because the vessels of the scalp do not contract in low temperatures. It was observed that insulating a policeman's head from the environment with a helmet led to accumulated $\mathrm{RH}$ (up to $63 \%$ in the final minutes of the experiment irrespective of thermal conditions) and heat $\left(35.8{ }^{\circ} \mathrm{C}\right.$ for thermoneutral conditions and $36.6^{\circ} \mathrm{C}$ for conditions of heat and noise) in the space under the helmet. This process caused higher internal temperature (on average by $0.65{ }^{\circ} \mathrm{C}$ in thermoneutral conditions and $0.23^{\circ} \mathrm{C}$ in conditions of heat and noise) and head skin temperature (on average by $2.81^{\circ} \mathrm{C}$ in thermoneutral conditions and $1.65{ }^{\circ} \mathrm{C}$ in conditions of heat and noise) than the values determined without a helmet. At the same time, this phenomenon aggravated subjective thermal sensation and assessment of dampness of skin and clothes during the experiment.

The concentration of $\mathrm{O}_{2}$ and $\mathrm{CO}_{2}$ in the space under the helmet during the tests is consistent with data in the literature. Measurements on subjects wearing integral helmets demonstrated that during parking, the concentration of $\mathrm{CO}_{2}$ under the helmet was $2 \%$ (permissible limit is over $3 \%$ ) 
[7]. In addition, the tests showed that an insufficient exchange of air caused a decrease in the concentration of $\mathrm{O}_{2}$ in the air breathed in by a motorcyclist to $\sim 17 \%$. This finding was confirmed in tests with motorcyclists parking, when the average concentration of $\mathrm{O}_{2}$ under the helmet decreased to $17-20 \%$ [7].

The level of psychomotor and cognitive functions also reflected changes in physiological parameters, which showed that attention can deteriorate in a subject wearing a helmet, under a combined influence of heat and noise. This result seems to confirm Pilcher, Nadler, Busch, et al.'s observations that concentration, perceptibility and reaction time are most susceptible to a negative influence of a hot environment [28].

Our results show that testing helmets and their approval should be based on an assessment of head skin temperature, core temperature, and the concentration of $\mathrm{O}_{2}$ and $\mathrm{CO}_{2}$ under the helmet, tested with the participation of volunteers. Those parameters can be used as indicators of psychological parameters (the subject's reaction time, attention and subjective feeling of mood and fatigue). It should also be emphasized that during the process of constructing helmets, special attention should be paid to ensuring maximum possible ventilation in the space between the helmet and the head to minimize the risk of excessive concentration of $\mathrm{CO}_{2}$ under the helmet and to provide a supply of fresh air during a motor ride.

From the perspective of a case study, it can be concluded that due to poor ventilation, wearing a helmet can cause an increase in the subject's head and core temperatures and, therefore, can deteriorate psychological parameters.

\section{REFERENCES}

1. Liu BC, Ivers R, Norton R, Boufous $\mathrm{S}$, Blows S, Lo SK. Helmets for preventing injury in motorcycle riders. Cochrane Database Syst Rev. 2008;(1):CD004333.

2. Association of European Motorcycle Manufacturers (ACEM). In-depth investigations of accidents involving powered two wheelers. Final report 1.2. Brussels, Belgium: ACEM; 2004. Retrieved May 14, 2012, from: http://ec. europa.eu/transport/roadsafety_library/

publications/maids_report_1_2_

september_2004.pdf

3. United Nations. Agreement concerning the adoption of uniform technical prescriptions for wheeled vehicles, equipment and parts which can be fitted and/or be used on wheeled vehicles and the conditions for reciprocal recognition of approvals granted on the basis of these prescriptions.

Addendum 21: regulation No. 22, revision. Uniform provisions concerning the approval of protective helmets and of their visors for drivers and passengers of motorcycles and mopeds. United Nations. 2002. Retrieved May 14, 2012, from: http:// www.unece.org/fileadmin/DAM/trans/ main/wp29/wp29regs/r022r4e.pdf

4. Bogerd CP, Brühwiler PA. Heat loss variations of full-face motorcycle helmets. Appl Ergon. 2009;40(2):161-4.

5. Bogerd CP, Brühwiler PA. The role of head tilt, hair and wind speed on forced convective heat loss through full-face motorcycle helmets: a thermal manikin study. Int J Ind Ergon. 2008;38(3-4): 346-53.

6. Greenbaum R, Malins AF, Davies R, Baskett PJ. Rebreathing in a subject wearing an integral crash helmet. Br Med J (Clin Res Ed). 1982;284(6318):774-5.

Retrieved May 14, 2012, from: http://www. ncbi.nlm.nih.gov/pmc/articles/

PMC1496391/?tool=pubmed

7. Brühwiler PA, Stämpfli R, Huber R, Camenzind $\mathrm{M} . \mathrm{CO}_{2}$ and $\mathrm{O}_{2}$ concentrations in integral motorcycle helmets. Appl Ergon. 2005;36(5):625-33.

8. Lower MC, Hurst DW, Claughton AR, Thomas A. Sources and levels of noise under motorcyclists' helmets. Proceedings of the Institute of Acoustics. 1994;16(Pt 2):319-25. Retrieved May 14, 2012, from: http://www.isvr.co.uk/reprints/ mcyclesioa.pdf

9. McKnight JA, McKnight SA. The effects of motorcycle helmets upon seeing and hearing. Accid Anal Prev. 1995;27(4): 493-501.

10. Horswill MS, Helman S. A behavioral comparison between motorcyclists and a matched group of non-motorcycling car 
drivers: factors influencing accident risk. Accid Anal Prev. 2003;35(4):589-97.

11. Chinn B, Canaple B, Derler S, Doyle D, Otte D, Schuller E, Willinger R. Cost 327: motorcycle safety helmets. Final report of the action. Luxembourg, Office for Official Publications of the European Communities; 2001. Retrieved May 14, 2012, from: http:// ec.europa.eu/transport/roadsafety_library/ publications/cost327_final_report.pdf

12. Gisolfi CV, Rohlf DP, Navarude SN, Hayes CL, Sayeed SA. Effects of wearing a helmet on thermal balance while cycling in the heat. Phys Sportsmed. 1988;16(1): 139-46.

13. Liu X, Abeysekera J, Shahnavaz H. Subjective evaluation of three helmets in cold laboratory and warm field conditions. Int J Ind Ergon. 1999;23(3):223-30.

14. Patel R, Mohan D. An improved motorcycle helmet design for tropical climates. Appl Ergon. 1993;24(6):427-31.

15. Fonseca GF. Physiological factors in protective helmet design. Natick, MA, USA: U.S. Army Research Institute of Environmental Medicine; 1976. Retrieved May 14, 2012, from: http://www.dtic.mil/ cgi-bin/GetTRDoc?Location $=\mathrm{U} 2 \&$ doc $=$ Get TRDoc.pdf \&AD=ADA051273

16. Wyon DP, Wyon I, Norin F. Effect of moderate heat stress on driver vigilance in a moving vehicle. Ergonomics. 1996;39(1):61-75.

17. Walker SM, Auckland TR, Dawson B. The combined effect of heat and carbon monoxide on the performance of motorsport athletes. Comp Biochem Physiol A Mol Integr Physiol. 2001;128(4):709-18.

18. Nunneley SA, Reader DC, Maldonado RJ. Head-temperature effects on physiology, comfort, and performance during hyperthermia. Aviat Space Environ Med. 1982;53(7):623-8.
19. Åstrand I. Aerobic work capacity in men and women with special reference to age. Acta Physiol Scand Suppl. 1960;49(169): 1-92.

20. Rozporządzenie Ministra Spraw Wewnętrznych i Administracji z dnia 30 listopada 2001 r. w sprawie umundurowania policjantów [Regulation of the Minister of Interior and Administration on police officers' uniforms]. Dz U. 2002;(3):item 29. Retrieved June 19, 2012, from: http://www.lex.pl/du-akt/-/akt/dz-u02-3-29.

21. Oyama T. Background and the present status of reaction time studies. Japanese Journal of Ergonomics. 1985;21(2);57-64.

22. Vienna Test System. Work performance series (ALS). Release 22.10. Mödling, Austria: Dr. G. Schuhfried; 2002.

23. Vienna Test System. Signal detection (SIGNAL). Version 5.00. Mödling, Austria: Dr. G. Schuhfried; 1996.

24. Piéron $\mathrm{H}$. The sensations: their functions, processes and mechanisms. New Haven, CT, USA: Yale University Press; 1952.

25. Baschera P, Grandjean EP. Effect of repetitive tasks with different degrees of difficulty on critical fusion frequency (CFF) and subjective state. Ergonomics. 1979;22(4):377-85.

26. American Society of Heating, Refrigerating and Air Conditioning Engineers (ASHRAE). Physiological principles for comfort and health. In: 1993 ASHRAE handbook-fundamentals. Atlanta, GA, USA: ASHRAE; 1985. p. 8.1-29.

27. Nielsen R, Endrusick TL. Sensations of temperature and humidity during alternative work/rest and the influence of underwear knit structure. Ergonomics. 1990;33(2):221-234.

28. Pilcher JJ, Nadler E, Busch C. Effects of hot and cold temperature exposure on performance: a meta-analytic review. Ergonomics. 2002;45(10):682-98. 